\title{
Research on Gasification of Solid Wastes in Civil Airports
}

\author{
Bo Li ${ }^{1,2 *}$, Mingxing Huang ${ }^{3}$, Wen Zhang ${ }^{1,2}$ \\ ${ }^{1}$ China Airport Construction Group Co., Ltd, 100101, China \\ ${ }^{2}$ Beijing Super-Creative Technology Co., Ltd, 100621, China \\ ${ }^{3}$ China National Environmental Protection Group, 100082, China
}

\begin{abstract}
After the airport is put into operation, a large amount of wastes generated every day will bring waste disposal pressure and ecological environment pressure to the airport and surrounding areas. This article expounds the current methods of airport waste disposal. According to the principle of waste reduction, harmless and reclamation, a set of solid waste gasification methods suitable for airports are proposed, which can reduce waste transportation and landfill costs, effectively control the impact of environmental pollution. At the same time, it can use waste heat to generate electricity to turn wastes into treasure and promote green airport construction.
\end{abstract}

\section{Introduction}

In recent years, with the rapid development of the aviation industry, passenger throughput has increased year by year, and the pressure on airport wastes disposal has been increasing, which has gradually become one of the problems affecting the surrounding environment of the airport. "Innovation, coordination, green, openness, and sharing" are the five development concepts in China's new era. The "13th Five-Year Plan for Civil Aviation Energy Conservation and Emission Reduction" requires that the wastes harmlessness and sewage treatment rates of new airports shall both reach more than $90 \%$. Strengthening centralized treatment and recycling of airport solid wastes, sewage, garbage, etc. puts higher requirements on the treatment of solid wastes at airports, and also points out the direction for the treatment of solid wastes at airports.

\section{Demand analysis of airport solid waste gasification}

\subsection{Airport wastes disposal status}

At present, the treatment of solid wastes at the airports generally adopts a municipal transfer method. The aviation wastes are first disinfected and then transported to the local municipal solid waste yards for landfill or incineration along with the airport domestic wastes. The aviation wastes from the quarantined/infected areas shall be transported directly by the designated professional organization for special treatment according to the disposal requirements of the hazardous wastes. This kind of treatment adds a burden to the local wastes disposal sites, and the transportation distance of the wastes is long, so secondary pollution is easily generated during

Table 1. Composition Table for Airport Waste transportation. At the same time, landfill will occupy a large area of land, and may cause a series of problems such as groundwater pollution and air pollution. In addition, the amount of sludge generated every day at the airports is also very large. Many airports' sludge treatment capacity fall short, and the treatment cost is high, resulting in a large accumulation of sludge, affecting the airport environment.

\subsection{Airport wastes gasification conditions}

Airport wastes are mainly categorized into aviation wastes and domestic wastes. Aviation wastes are the domestic wastes generated by passengers on the plane, mainly including newspapers, small food packaging boxes, a small amount of residual food, disposable paper cups, plastic bottles and cans, etc. Recyclables account for a large proportion. Domestic wastes are roughly divided into two categories, and one is ordinary domestic wastes, mainly from the wastes generated on the airside and land side of the terminal buildings, the office wastes generated by the organizations resided at airport, and the domestic wastes generated in the airport living areas. The other category is aviation food processing wastes, mainly the wastes generated during the production and processing by the airport food distribution centers, and the organic wastes generated by the aerial food processing are the main component. In general, the solid wastes at the airports are higher in quality than the municipal solid wastes, and the calorific value produced is also higher, which is more suitable for gasification. The amount of wastes per day at the airports is generally less than 100 tons, and it is also very suitable for use of small gasifiers. As it is shown in Table 1. 


\begin{tabular}{|c|c|c|c|c|c|}
\hline \multirow{2}{*}{\multicolumn{2}{|c|}{ Aviation waste }} & \multicolumn{4}{|c|}{ Household waste } \\
\hline & & \multicolumn{2}{|c|}{ Ordinary household waste } & \multicolumn{2}{|c|}{ Air food processing waste } \\
\hline Category & Proportion & Category & Proportion & Category & Proportion \\
\hline Paper & $27 \%$ & Paper & $25 \%$ & Paper & $9 \%$ \\
\hline Plastic & $20 \%$ & Plastic & $38 \%$ & Plastic & $10 \%$ \\
\hline Abandoned meals & $32 \%$ & Glass & $0.5 \%$ & Metal & $2 \%$ \\
\hline $\begin{array}{l}\text { Aluminum foil lunch } \\
\text { box }\end{array}$ & $1 \%$ & Metal & $1 \%$ & Abandoned meals & $65 \%$ \\
\hline Water & $19 \%$ & Organics & $20 \%$ & Water & $13 \%$ \\
\hline \multirow[t]{3}{*}{ Others } & $1 \%$ & Water & $11 \%$ & Others & $1 \%$ \\
\hline & & Slag & $3 \%$ & & \\
\hline & & Others & $1.5 \%$ & & \\
\hline
\end{tabular}

\section{The choice of airport solid waste gasification technologies}

\subsection{Current status and trends of technology development}

The United States has not built a waste to energy plant since 1995. Europe has adopted landfill and incineration taxes to control the application of landfill and incineration technologies.

Developed countries have invested the most in the treatment of domestic wastes by gasification, and gasification is constantly applied to commercialization projects. The waste gasification technology is reliable and its cost is reasonable, and it conforms to the development law of the waste treatment industry. As a new generation of technology for replacing domestic waste incineration, it will be commonly adopted by the domestic waste disposal inevitably in the future.

\subsection{Gasification technology selection}

At present, the domestic wastes gasifiers with more applications and more mature technologies mainly include fixed bed gasifiers, fluidized bed gasifiers, moving bed gasifiers, etc..

The fixed bed gasifier is more mature than other furnace types. This furnace type is adopted more often by waste gasification plants at home and abroad. It is reliable in operation, adaptable to wastes, and can adapt to the characteristics of domestic waste complex components to ensure complete combustion of wastes. Its equipment service life is long, and the operation is stable, and the maintenance is easy. Therefore, it is more suitable to use fixed bed gasifier technology for airport solid waste treatment.

\section{Airport solid waste gasification technology solutions and basic process}

\subsection{Technical solutions}

The airport solid waste treatment technology solutions are mainly to build a high-standard solid waste treatment facility, using gasification incineration technology for waste treatment, supplemented by sludge drying and wastes sorting to achieve synergistic gasification and incineration between wastes and sewage sludge to address airport wastes and sludge, while recovering high valueadded substances and energy from airport wastes.

The main process is to collect the airside and land-side wastes and transport them to the solid waste treatment station, offload the wastes to the chain conveyor, and then enter the automatic sorting after breaking the bags through the bag breaking machine, and then the highly valueadded substances such as metals, plastic bottles, cartons, paperboard and cardboard, etc. are sorted, and the sorted wastes enters the wastes storage pit. The sludge from the sewage plant is transported to the wastes storage pit after being dried at a low temperature. The wastes in the storage pit are fed to the gasification combustion system by the grab bucket to realize the reclamation, reduction and harmless treatment of the wastes. As it is shown in Figure 1. 


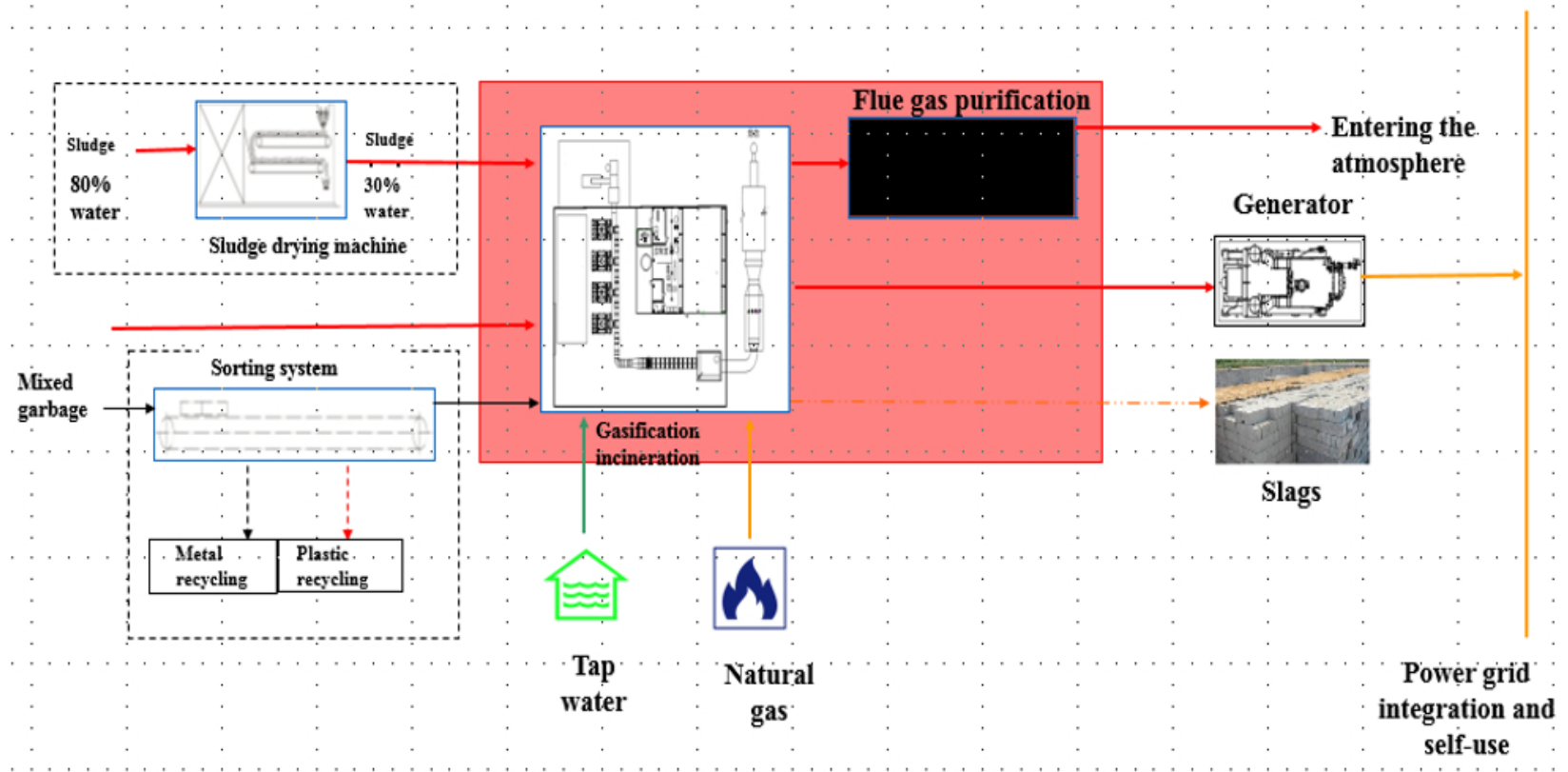

Fig.1 Airport solid waste gasification technology roadmap

\subsection{Wastes pre-sorting}

Wastes pre-sorting is the first step in solid waste treatment. It is mainly for the recovery of high value-added materials from aircraft and terminal wastes by means of bag breaking, magnetic separation, photoelectric sorting and vortex selection.

\subsection{Sludge treatment}

There are many sludge treatment methods, but the relatively mature treatment method for small-scale sludge treatment technology on the market is low-temperature drying technology, that is, using dehumidification heat pump + belt drying machine and adopting hot air circulation on sludge-condensation dehumidification drying method to achieve sludge drying.

\subsection{Gasification}

The gasification combustion system comprises a plurality of main gasification chambers and one or more secondary combustion chambers (the number of primary gasification chambers and secondary combustion chambers is determined according to the scale of waste treatment), and a plurality of main gasification chambers are connected to the secondary combustion chambers via a common synthesis gas manifold. Dampers are equipped on the outlet duct of each main gasification chamber and the inlet duct of the secondary combustion chamber, controlling the flow rate of the main gasification chamber outlet gas and balancing the pressure between each main gasification chamber while providing the secondary combustion system with stable syngas supply to ensure constant heat and power output of waste residual heat boilers and turbine generator units. When necessary, natural gas or other fuels can be used as alternative to syngas to maintain a stable heat supply to the secondary combustion system.

\subsection{Flue gas purification}

While reliably and stably handling wastes, it is a must to strictly enforce environmental standards and reduce pollutant discharge concentrations. Since there is no relevant standard for the treatment of domestic wastes by gasification technology, the purification of flue gas shall be carried out in accordance with the highest standards of national and local standards. It mainly adopts the combination of two-stage deacidification, two-stage dust removal, SCR denitrification and flue gas de-whitening.

\subsection{Energy utilization}

Domestic wastes are gasified and burned to produce hightemperature flue gas, which can usually be used. Considering that, in terms of energy utilization, the power generation is more convenient than heating supply or hot water, and with wider application, then the recommended energy utilization mode is power generation.

\subsection{Economic and social benefits}

The use of waste gasification technology can greatly reduce the amount of waste transportation. If the daily waste disposal of the airport is $80 \mathrm{~d}$ and 20 tons of sludge ( $80 \%$ water content), the daily landfill volume is only $5 \%$ of the daily wastes production, which effectively controls the secondary pollution of the wastes. It is of great significance to improve the airport environment and effectively protect the normal operation of the airport.

\subsubsection{Ultra-low emission of flue gas}


Flue gas purification is subject to the highest standards, and exerted via multiple ways combined to ensure that the flue gas purified can stably meet ultra-low emission requirements and reduce environmental impact.

\subsubsection{Less occupation of land}

The sequencing batch gasification system adopts a modular design with small volume, low failure rate and compact structure. Compared with the grate furnace incineration system, the unit processing capacity occupies less land, and the land is saved.

\subsubsection{Less waste water}

The collected wastes will enter the gasifier directly, and no leachate will be produced. The steam turbine will be air-cooled and no waste water will be produced.

\subsubsection{Synergistic treatment of sludge}

It can co-process the sludge generated by the airport sewage plant and the wastes to solve the next steps of the sludge of the sewage plant.

\subsubsection{Fully automatic control}

Wastes sorting system, gasification system, flue gas purification system, steam turbine power generation system all adopt fully automatic control, reducing labor costs.

\subsubsection{Carbon emission reduction and green power}

It can achieve annual $\mathrm{CO} 2$ emission reduction of 8,600 tons, and can deliver 8 million $\mathrm{kWh}$ of electricity to the outside, achieving energy efficiency and emissions reductions.

\subsubsection{Flexible wastes disposal scale}

The sorting system can adjust the running time to adapt to the change of the amount of wastes. The gasification system adjusts the number and running time of the gasification chambers according to the amount of wastes, and has flexible wastes disposal capacity and is more economical.

\section{Conclusion}

Airport waste gasification can fundamentally reverse the passive situation of airport waste outward transportation for landfill disposal. By gasification of airport solid wastes, using waste heat to generate electricity to turn wastes into treasure, can save energy, alleviate power shortage, improve the comprehensive utilization of airport resources, is also aligned with the airport's green construction concept, and is worthy of promotion and application.

\section{Acknowledgement}

This work is funded by CAAC Technology Innovation Guidance Program 'Research on Energy Consumption Management of Civil Airport Terminals' (MHRD20140319).

\section{References}

1. Y H. Liang, T Wei, Application Status and Development Tendency of Refuse Gasification Technology, Environmental Protection Industry in China,3,50(2016)

2. 13th Five-Year Plan for Energy Conservation and Emission Reduction of Civil Aviation,CAAC(2017)

3. X Y.Tang, G T.Gao, Design on Process Scheme of Solid Waste Resourceful Utilization in Green Airport, Environmental Science and Management, 33(12), 162(2008)

4. B.Shen, F.Du, X L.Chen, Consideration on Problems and Future Work of Domestic Airport Aeronautical Waste Management and Disposal, Energy Conservation and Environmental Protection in Traffic, 14(4),106,(2018)

5. Zhao Lianmiao,Gong Shen, Application of Solid Waste Gasification Technology in China, Environmental Protection Science, 44(5) ,108,( 2018)

6. Xiao Bo, Wang Yingying, Su Qion, The Research of Treating Municipal Solid Waste by Gasification, China Resources Comprehensive Utilization, 24(10), 18 (2006) 